\title{
Increasing Rate of Hospitalization For Severe Peptic Ulcer After The Pandemic: Digestive Emergency Data From Two Regional Hospitals.
}

\section{Chenxing Jian}

Huazhong University of Science and Technology

\section{Zili Zhou}

University of Electronic Science and Technology of China

Chunkang Yang

Fujian Medical University Cancer Hospital

Ning Zhao

Huazhong University of Science and Technology

Haijun Bao

Huazhong University of Science and Technology

Shengbo Han

Huazhong University of Science and Technology

Jinhuang Chen

Huazhong University of Science and Technology

Xiaogang Shu ( $\nabla$ sxg678@yahoo.com )

Huazhong University of Science and Technology

\section{Research Article}

Keywords: pandemic, outbreak, patients, health

Posted Date: December 1st, 2021

DOI: https://doi.org/10.21203/rs.3.rs-1073000/v1

License: (1) (1) This work is licensed under a Creative Commons Attribution 4.0 International License. Read Full License 


\section{Abstract}

With the introduction of the coronavirus disease 2019 (COVID-19) vaccine, the pandemic has abated. However, the virus has not been completely contained, and some of the potential effects of the outbreak have not been thoroughly studied. We collected data from two regional emergency centers from May to November 2015-2019, before the outbreak, and from May to November 2020, after the outbreak. We evaluated the incidence of each major type of digestive disease before and after the pandemic in adults at two hospitals, which experienced COVID-19 outbreaks with varying severity. A total of 11,336 patients were enrolled in the study (PUTIAN, $n=5503$, UNION, $n=5891$ ). From 2015 to 2019 , the numbers of patients at the two hospitals increased steadily, but in 2020, the number of patients at UNION declined. The constituent ratios of diseases in each year in the two hospitals differed. The number of patients with peptic ulcer in 2020 was significantly different from that in each year from 2015 to 2019 (PUTIAN 20152020, 16.6\%, 20.0\%, 16.6\%, 18.3\%, 21.1\%, 37.1\%; UNION 2015-2020, 31.5\%, 34.6\%, 31.6\%, 31.3\%, 31.7\%, $43.7 \%$, respectively). The rates of peptic ulcer increased dramatically in both hospitals in 2020. An increase in the incidence of severe peptic ulcer was observed after the pandemic compared to the same period in previous nonpandemic years. Therefore, these factors should be considered in the formulation of public health strategies and the allocation of medical resources in the postepidemic era.

\section{Introduction}

Since December 2019, the novel coronavirus has spread worldwide ${ }^{1,2}$, affecting more than 240 million people, with more than 5 million deaths. Severe acute respiratory syndrome coronavirus 2 (SARS-CoV-2) infection can affect multiple organs and result in mortality ${ }^{3-1}$; it can also indirectly affect other aspects of health systems ${ }^{14}$. Scholars believe that pandemics can affect mental health, economic status, job opportunities and other social factors ${ }^{15}$. A study ${ }^{16}$ from Germany showed that the pandemic also changed the emergency medical situation, as the numbers of cholecystectomies and appendectomies in the pandemic year were significantly lower than those in the reference year of 2019. However, it is unclear whether such effects will sustain in the postpandemic era.

In the postepidemic era, people will continue to experience great psychological pressure, and such pressure may induce the development many diseases, which should attract the attention of medical personnel. After April 8, 2020, the medical activities in medical institutions in Wuhan, which was the most severely affected area in China, gradually returned to normal. However, during the recovery period, some changes were observed, such as the number of visits and the proportions of visits for certain diseases. Such data is of importance for the allocation of medical resources after an epidemic. The present study primarily focuses on changes in the characteristics of general surgical emergencies, particularly those involving the digestive system, after control of the epidemic. We also compared the situations in two different regions. At present, few articles have reported similar experiences in the field of emergency surgery. We intend to share our experiences with the hope that they will help our colleagues around the world in the postepidemic period. 


\section{Methods}

This was a retrospective study. We collected data from two regional emergency centers (UNION and PUTIAN) from May to November 2015, before the outbreak, and May to November 2020, after the outbreak. The reason we analyzed count data from May to November in each year rather than the whole year is that Wuhan was under lockdown from January 23, 2020, to April 8, 2020; medical practice gradually returned to normal after this period, so we excluded data from January to April. As the initial cases were identified in December 2019, medical practice was affected to some extent, so we also excluded data from December. Finally, we collected, statistically analyzed and compared the data from the two hospitals during the same period from May to November 2015 to 2019.

We evaluated the incidence of each major type of digestive system disease in adults at the two hospitals, which experienced outbreaks of varying severity, before and after the pandemic. We selected all hospitalized adult patients within this time period and excluded patients with rare diseases that could not be effectively compared and those with non-digestive system diseases. For the sake of comparability between the two hospitals, we excluded adolescents younger than 18 years old.

We collected data on the following digestive system diseases from both hospitals: acute appendicitis, acute pancreatitis, biliary tract inflammation, bowel obstruction or bleeding, esophageal and gastric variceal bleeding, hernia, liver abscess or cancer, peptic ulcer, and trauma. Due to different pathogenic factors, esophageal and gastric variceal bleeding and peptic ulcer bleeding were analyzed separately. Peptic ulcer was defined as a severe peptic ulcer with bleeding, obstruction, and perforation, and both benign and malignant tumors of the stomach and duodenum resulting from emergency cases were considered peptic ulcer. Biliary tract inflammation included tumors, stones and inflammation of the biliary tract caused by other causes. Bowel obstruction or bleeding included postoperative intestinal obstruction below the jejunum, primary intestinal obstruction, and intestinal bleeding. Trauma was defined as injury to a digestive system organ caused by various mechanisms. Liver abscess or cancer was defined as a liver abscess, liver rupture due to cancer, or liver cancer with severe abdominal pain. Hernia was defined as a hernia in the abdominal area involving the digestive system.

Finally, we obtained the data of 11,394 cases in 12,285 patients (shown in Fig 1). SPSS20.0 software was used to analyze the data. The chi-square test was used for count data, and analysis of variance was used for measurement data. Bonferroni correction was applied to analyze the peptic ulcer composition ratio in 2020 compared with those in each year from 2015 to 2019.

All methods in this study were performed in accordance with Declaration of Helsinki.The data are anonymous, and the requirement for informed consent was therefore waived.The protocol of this study and informed consent exemption were approved by the Ethics Committee of Putian University Affiliated Hospital (No. 2021028).

\section{Results}


A total of 11,394 patients were enrolled in the study (PUTIAN, $n=5503$ ) (UNION, $n=5891$ ), and the proportion of male patients was approximately the same at both hospitals, at $3360(61.1 \%)$ and 3680 (62.5\%), respectively. The ages of the patients were $55.8 \pm 18.4$ years (PUTIAN) and $54.3 \pm 15.8$ years (UNION). From 2015 to 2019, the total number of emergency digestive system-related cases in the two hospitals increased steadily, but in 2020, the number of cases in UNION declined, while the same was not observed in PUTIAN, which did not experience a lockdown during the same period. This may be explained by the fact that medical practice at UNION did not completely return to normal after the lockdown (shown in Table 1). In the two hospitals, from 2015 to 2020, there were no significant differences in the sex ratio in each year, but there were significant differences in the age compositions, as shown in Table 2. There seemed to be a trend of increasing age among patients.

As show in Table 3 and Table 4, statistical analysis revealed that the constituent ratios of the diseases of interest in each year in the two hospitals were different. As seen in Table 3 and Figure 2, from 2015 to 2020 , the numbers of cases of other diseases of interest, except peptic ulcer, generally showed mild fluctuations, but the constituent ratio did not change significantly. Interestingly, in 2020, there was a sudden and significant increase in the proportion of peptic ulcer cases $(2015-2020, \%=16.6 \%, 20.0 \%$, $16.6 \%, 18.3 \%, 21.1 \%, 37.1 \%$, respectively) in PUTIAN. The same phenomenon also occurred in UNION, where, in 2020, the proportion of peptic ulcer cases also suddenly and sharply increased (2015-2020, $\%=31.5 \%, 34.6 \%, 31.6 \%, 31.3 \%, 31.7 \%, 43.7 \%$, respectively), while it remained stable or fluctuated slightly (shown in Table 4 and Figure 3 ) in previous years.

In view of the above results, we conducted further statistical analysis and compared the peptic ulcer incidence with the total incidence of all other diseases before and after the pandemic (as shown in Table 5, Figure3A, and Figure3B). The peptic ulcer proportion in 2020 was significantly different from those in each year from 2015 to 2019 . Therefore, considering the statistical results together with the number of patients, we believe that the peptic ulcer incidence increased dramatically in both hospitals in 2020 .

\section{Discussion}

Regarding the demographic data in this study, the ratio of males to females was similar in both hospitals. As seen in Table 2, the average age of patients in the two hospitals was similar, with a seemingly increasing trend. Geographically, the two hospitals are important medical centers in their respective regions. Although they cannot completely represent the situations of the two regions, the study still has important guiding significance. In the future, if possible, more hospital data should be included in additional in-depth population-based epidemiological studies.

After the pandemic, the number of emergency department visits at UNION did not return the normal level. On the one hand, patients in the region may have remained concerned about SARS-CoV-2 exposure in hospital settings; on the other hand, the health system may not have fully recovered from the crisis. The same situation was not observed at PUTIAN, possibly because the number of patients infected with the 
virus during the pandemic was small and the medical system did not collapse; thus, after a period of adjustment, the situation quickly returned to normal.

The composition of various diseases in the emergency department prior to the pandemic was basically stable, with some diseases showing slight fluctuations. There was a dramatic increase in the proportion of peptic ulcer after the pandemic, and this was observed in both hospitals. In Wuhan, the first city to report the outbreak, the health care system was severely affected, and for some time, the health care system was in a state of collapse. PUTIAN, though not located in a severely affected area, also experienced a period of social restrictions and community lockdowns during the pandemic. Fear that the health system will collapse or collapse again after the resumption of normal medical practice and the additional virus testing procedures during the treatment process may lead to a great psychological burden on citizens. While the total number of hospitalizations decreased, the number of peptic ulcer cases increased in not only proportion but also number, so the increase in the relative percentage of hospitalizations for peptic ulcer was unlikely to be due to the lower incidence of hospitalizations for other types of diseases. The results of the increased incidence of peptic ulcer observed in our study may be related to stress. Another explanation may be that patients with relatively mild symptoms did not seek medical attention early in the pandemic, resulting in a larger number of more serious cases later.

Our previous study ${ }^{17}$ showed the effects of viral infections on the digestive system. Medical colleagues from the Kingdom of Saudi Arabia have also reported such effects ${ }^{18}$. However, all the patients in this study were negative for SARS-CoV-2 infection, so peptic ulcer was not directly caused by the virus. Of course, some researchers have already found that in addition to symptoms caused by infection, indirect effects of the pandemic are also prevalent. For example, the breakdown of health systems, social restrictions, and the closure of cities or communities during epidemics indirectly change the behavior of citizens and indirectly affect the incidence of some diseases ${ }^{19}$. French researchers found a dramatic increase in nontraumatic out-of-hospital cardiac arrest in Paris during the pandemic ${ }^{14}$. An increase in the incidence of peptic ulcer was also observed after the Japanese earthquake ${ }^{20}$. Therefore, for the public, the stress associated with a large, catastrophic event is high, and it is likely to remain at a high level for some time. Our study showed similar results, with dramatic increases in the incidence of peptic ulcer in different geographic areas in the seven months after control of the pandemic, which may be related to social stress. Therefore, we suggest that the relevant departments should provide psychological counseling to the public in a timely manner. We analyzed the incidence among age groups, but there was no significant difference; it seemed that all adult patients were affected.

To date, the virus is still being transmitted worldwide, but it is believed that virus transmission will gradually be controlled in the near future as many countries begin to vaccinate. China, supported by a strict lockdown policy and highly effective epidemiological investigations, has basically contained the epidemic. This does not mean, however, that the longer-term effects of the pandemic can be ignored. Over the past year, small outbreaks in some parts of China have required lockdown measures and strict social restrictions to control community transmission. Therefore, health care systems still need to pay attention 
to the lasting effects of the pandemic and accordingly adjust policies and balance the allocation of health resources, including reallocating emergency resources, in hospitals in affected regions. The results of this study can provide a reference for the allocation of medical resources after a pandemic. Additionally, it is necessary to provide psychological counseling for the masses, especially those who have been patients.

This study has some limitations. First, both hospitals were major emergency centers in the region, but they were not the only ones, and the study was not a demographic-based observational study, so the results could be biased. Second, the study was limited to two regions and is not fully representative of national or global conditions, so it is necessary to integrate comparable data from other regions or countries in the future to further confirm these findings and explore the pathogenesis and effective prevention measures. Third, all the patients in this study were adults aged more than 18 years, so it is not known whether the same results would be found in adolescents. Fourth, this study was limited to emergency cases involving the digestive system, and the effects on other organ systems are unknown.

\section{Conclusions}

An increase in the incidence of severe peptic ulcer was observed after the pandemic compared to the same period in previous nonpandemic years. Therefore, these factors should be considered in the formulation of public health strategies and the allocation of medical resources in the postepidemic era.

\section{Declarations}

Statement of Ethics. This study was approved by the Ethics Committee of Putian University Affiliated Hospital (No. 2021028).

Author contributions Conceptualization,C.X.J,C.K.Y,X.G.S;Data curation,C.X.J;Formal analysis,C.X.J, Z.L.Z; Methodology, C.X.J, Z.L.Z, C.K.Y, N.Z, H.J.B, S.B.H, J.H.C, X.G.S; Project administration, C.X.J, Z.L.Z, J.H.C, X.G.S; Resources,C.X.J, J.H.C, X.G.S; Supervision, C.X.J, Z.L.Z, C.K.Y, J.H.C, X.G.S; Validation,C.X.J,X.G.S ; Visualization, C.X.J, Z.L.Z, J.H.C.; Writing-review and editing,C.X.J, Z.L.Z, J.H.C.

Disclosure. The authors do not have any competing interests to declare regarding this article. This study was supported by the National Natural Science Foundation of China (No. 82072744), Research Fund of Union Hospital (No. 02.03.2018-123), and Natural Science Foundation of Fujian Province, China (No. 2021J011371).

\section{References}

1. Zhou, F., Yu, T., Du R, Fan, G., Liu, Y., Liu, Z., Xiang, J., Wang, Y., Song, B., Gu, X., Guan, L., Wei, Y., Li, H., Wu, X., Xu, J., Tu, S., Zhang, Y., Chen, H. and Cao, B. Clinical course and risk factors for mortality of adult inpatients with COVID-19 in Wuhan, China: a retrospective cohort study. Lancet, 2020. 395(10229): p. 1054-1062. 
2. Wu, Y., Ho, W., Huang, Y., Jin, D. Y., Li, S., Liu, S. L., Liu, X., Qiu, J., Sang, Y., Wang, Q., Yuen, K. Y. and Zheng, Z. M. SARS-CoV-2 is an appropriate name for the new coronavirus. Lancet, 2020. 395(10228): p. 949-950.

3. Hendren, N. S., Drazner, M. H., Bozkurt, B. and Cooper, L. J. Description and Proposed Management of the Acute COVID-19 Cardiovascular Syndrome. Circulation, 2020. 141(23): p. 1903-1914.

4. Behzad, S., Aghaghazvini, L., Radmard, A. R. and Gholamrezanezhad, A. Extrapulmonary manifestations of COVID-19: Radiologic and clinical overview. Clin Imaging, 2020. 66: p. 35-41.

5. Pousa, P. A., Mendonca, T., Oliveira, E. A. and Simoes-E-Silva, A. C.Extrapulmonary manifestations of COVID-19 in children: a comprehensive review and pathophysiological considerations. J Pediatr (Rio J), 2021. 97(2): p. 116-139.

6. Abobaker, A., Raba, A. A. and Alzwi, A. Extrapulmonary and atypical clinical presentations of COVID-19. J Med Virol, 2020. 92(11): p. 2458-2464.

7. Zheng, K. I., Feng, G., Liu, W. Y., Targher, G., Byrne, C. D. and Zheng, M. H. Extrapulmonary complications of COVID-19: A multisystem disease? J Med Virol, 2021. 93(1): p. 323-335.

8. AlSamman, M., Caggiula, A., Ganguli, S., Misak, M. and Pourmand, A. Non-respiratory presentations of COVID-19, a clinical review. Am J Emerg Med, 2020. 38(11): p. 2444-2454.

9. Adukia, S. A., Ruhatiya, R. S., Maheshwarappa, H. M., Manjunath, R. B. and Jain, G. N. Extrapulmonary Features of COVID-19: A Concise Review. Indian J Crit Care Med, 2020. 24(7): p. 575-580.

10. Bradley, B. T., Maioli, H., Johnston, R., Chaudhry, I., Fink, S. L., Xu, H., Najafian, B., Deutsch, G., Lacy, J. M., Williams, T., Yarid, N. and Marshall, D. A. Histopathology and ultrastructural findings of fatal COVID-19 infections in Washington State: a case series. Lancet, 2020. 396(10247): p. 320-332.

11. Ronco, C., Reis, T. and Husain-Syed, F. Husain-Syed, Management of acute kidney injury in patients with COVID-19. Lancet Respir Med, 2020. 8(7): p. 738-742.

12. Nicolai, L., Leunig, A., Brambs, S., Kaiser, R., Weinberger, T., Weigand, M., Muenchhoff, M., Hellmuth, J. C., Ledderose, S., Schulz, H., Scherer, C., Rudelius, M., Zoller, M., Hochter, D., Keppler, O., Teupser, D., Zwissler, B., von Bergwelt-Baildon, M., Kaab, S., Massberg, S., Pekayvaz, K. and Stark, K. Immunothrombotic Dysregulation in COVID-19 Pneumonia Is Associated With Respiratory Failure and Coagulopathy. Circulation, 2020. 142(12): p. 1176-1189.

13. Metkus, T. S., Sokoll, L. J., Barth, A. S., Czarny, M. J., Hays, A. G., Lowenstein, C. J., Michos, E. D., Nolley, E. P., Post, W. S., Resar, J. R., Thiemann, D. R., Trost, J. C. and Hasan, R. K. Myocardial Injury in Severe COVID-19 Compared With Non-COVID-19 Acute Respiratory Distress Syndrome. Circulation, 2021. 143(6): p. 553-565. 
14. Marijon, E., Karam, N., Jost, D., Perrot, D., Frattini, B., Derkenne, C., Sharifzadehgan, A., Waldmann, V., Beganton, F., Narayanan, K., Lafont, A., Bougouin, W. and Jouven, X. Out-of-hospital cardiac arrest during the COVID-19 pandemic in Paris, France: a population-based, observational study. Lancet Public Health, 2020. 5(8): p. e437-e443.

15. Whitehead, M., Taylor-Robinson, D. and Barr, B.Poverty, health, and covid-19. BMJ, 2021. 372: p. n376.

16. Koch, F., Hohenstein, S., Bollmann, A., Meier-Hellmann, A., Kuhlen, R. and Ritz, J. P. [Has the COVID19 Pandemic Changed the Emergency Situation in German Clinics? A Nationwide Analysis of Routine Data from 73 Acute Hospitals]. Zentralb/ Chir, 2021.

17. Zhou, Z., Zhao, N., Shu, Y., Han, S., Chen, B. and Shu, X. Effect of Gastrointestinal Symptoms in Patients With COVID-19. Gastroenterology, 2020. 158(8): p. 2294-2297.

18. Merdad, G. A., Seadawi, L. E. and Mustafa, A. A. Peptic ulcer associated with COVID-19 in Saudi Arabia. Saudi Med J, 2021. 42(9): p. 1036-1040.

19. Senthilingam, M. Covid-19 has made the obesity epidemic worse, but failed to ignite enough action. BMJ, 2021. 372: p. n411.

20. Kanno, T., lijima, K., Abe, Y., Koike, T., Shimada, N., Hoshi, T., Sano, N., Ohyauchi, M., Ito, H., Atsumi, T., Konishi, H., Asonuma, S. and Shimosegawa, T. Peptic ulcers after the Great East Japan earthquake and tsunami: possible existence of psychosocial stress ulcers in humans. J Gastroenterol, 2013. 48(4): p. 483-90.

\section{Tables}

Table 1-Demographic Characteristics and Number of patient visits per year 


\begin{tabular}{|c|c|c|}
\hline & PUTIANヌnヌ\%ヌ & UNIONヌnヌ\%区 \\
\hline & $\bigotimes n=5503 \rrbracket$ & $\llbracket n=5891 \rrbracket$ \\
\hline \multicolumn{3}{|l|}{ Gender } \\
\hline male & $3360 \rrbracket 61.1 \rrbracket$ & $3680 \rrbracket 62.5 \rrbracket$ \\
\hline female & 2143囚38.9囚 & $2211 \otimes 37.5 \rrbracket$ \\
\hline Age $\ y \rrbracket$ & $55.8 \pm 18.4$ & $54.3 \pm 15.8$ \\
\hline \multicolumn{3}{|c|}{ Admission time $\mathbb{y} \mathbb{\|}$} \\
\hline 2015 & 795®14.4】 & 708ه12.0邓 \\
\hline 2016 & 840冈15.3囚 & 827ه14.0囚 \\
\hline 2017 & 818ه14.9囚 & 1009ه17.1区 \\
\hline 2018 & $930 \rrbracket 16.9 \rrbracket$ & 1107ه18.8】 \\
\hline 2019 & $972 \bowtie 17.7 \rrbracket$ & 1318ه22.4】 \\
\hline 2020 & 1148ه20.9ه & 922邓15.7凶 \\
\hline
\end{tabular}

Table 2-The gender and age distribution of the two hospitals in different years

\begin{tabular}{|c|c|c|c|c|c|c|c|}
\hline & 2015 & 2016 & 2017 & 2018 & 2019 & 2020 & $\mathrm{P}$ \\
\hline \multicolumn{8}{|l|}{ PUTIAN } \\
\hline Gender & & & & & & & 0.104 \\
\hline male & $455(57.2)$ & $513(61.1)$ & $486(59.4)$ & $582(62.6)$ & $598(61.5)$ & $726(63.2)$ & \\
\hline female & $340(42.8)$ & $327(38.9)$ & $332(40.6)$ & $348(37.4)$ & $374(38.5)$ & $422(36.8)$ & \\
\hline Age $(y)$ & $54.1 \pm 18.5$ & $54.4 \pm 18.4$ & $53.0 \pm 18.8$ & $56.8 \pm 18.2$ & $58.0 \pm 18.0$ & $57.3 \pm 18.3$ & 0.000 \\
\hline \multicolumn{8}{|l|}{ UNION } \\
\hline Gender & & & & & & & 0.258 \\
\hline male & $446(63.0)$ & $537(64.9)$ & $646(64.0)$ & $683(61.7)$ & $793(60.2)$ & $575(62.4)$ & \\
\hline female & $262(37.0)$ & $290(35.1)$ & $363(36.0)$ & $424(38.3)$ & $525(39.8)$ & $347(37.6)$ & \\
\hline Age $(y)$ & $53.4 \pm 16.8$ & $52.0 \pm 15.6$ & $54.1 \pm 16.0$ & $54.9 \pm 15.8$ & $55.4 \pm 15.2$ & $55.4 \pm 15.7$ & 0.000 \\
\hline
\end{tabular}

Table 3-The disease composition ratio in different years*(PUTIANヌnヌ\%)) 


\begin{tabular}{|c|c|c|c|c|c|c|}
\hline & $\begin{array}{l}2015 \\
\bigotimes n=795 \rrbracket\end{array}$ & $\begin{array}{l}2016 \\
\bigotimes n=840 \rrbracket\end{array}$ & $\begin{array}{l}2017 \\
\Downarrow n=818 \rrbracket\end{array}$ & $\begin{array}{l}2018 \\
\bigotimes n=930 \bigotimes\end{array}$ & $\begin{array}{l}2019 \\
\bigotimes n=972 \rrbracket\end{array}$ & $\begin{array}{l}2020 \\
\bigotimes n=1148 \bigotimes\end{array}$ \\
\hline $\begin{array}{l}\text { Acute Appendicitis } \\
\llbracket n=1133 \rrbracket\end{array}$ & $252(31.7)$ & $201(23.9)$ & $201(24.6)$ & 164(17.6) & $148(15.2)$ & $167(14.5)$ \\
\hline $\begin{array}{l}\text { Acute Pancreatitis } \\
\bigotimes n=571 \rrbracket\end{array}$ & 77(9.7) & $102(12.1)$ & $73(8.9)$ & $112(12.0)$ & $90(9.3)$ & $117(10.2)$ \\
\hline $\begin{array}{l}\text { Biliary Tract } \\
\text { Inflammation } \\
\bigotimes n=1072 \rrbracket\end{array}$ & $160(20.1)$ & $161(19.2)$ & $191(23.3)$ & $214(23.0)$ & 184(18.9) & $162(14.1)$ \\
\hline $\begin{array}{l}\text { Bowel Obstruction or } \\
\text { Bleeding }\end{array}$ & $119(15.0)$ & $130(15.5)$ & $121(14.8)$ & $150(16.1)$ & $200(20.6)$ & $165(14.4)$ \\
\hline $\begin{array}{l}\bigotimes n=885 \rrbracket \\
\text { Esophageal and } \\
\text { Gastric Varices }\end{array}$ & $11(1)$ & مח ( & $0 \Gamma^{2} 1$ 1) & ? 77 & $5[(57)$ & $50(51)$ \\
\hline $\begin{array}{l}\text { Bleeding } \\
\bigotimes n=204 \rrbracket \\
\text { Hernia }\end{array}$ & 11(1.4) & 20(2.4) & 25(3.1) & $34(3.7)$ & $55(5.7)$ & 59(5.1) \\
\hline$\bigotimes n=142 \rrbracket$ & 29(3.6) & $27(3.2)$ & $18(2.2)$ & $21(2.3)$ & $33(3.4)$ & $14(1.2)$ \\
\hline $\begin{array}{l}\text { Liver Abscess or } \\
\text { Cancer } \\
\bigotimes n=132 \rrbracket\end{array}$ & $4(0.5)$ & $23(2.7)$ & $28(3.4)$ & $32(3.4)$ & $17(1.7)$ & $28(2.4)$ \\
\hline $\begin{array}{l}\text { Peptic Ulcer } \\
\bigotimes n=1237 \rrbracket\end{array}$ & $132(16.6)$ & $168(20.0)$ & $136(16.6)$ & $170(18.3)$ & $205(21.1)$ & $426(37.1)$ \\
\hline $\begin{array}{l}\text { Trauma } \\
\bigotimes n=127 \rrbracket\end{array}$ & $11(1.4)$ & $8(1.0)$ & $25(3.1)$ & $33(3.5)$ & $40(4.1)$ & $10(0.9)$ \\
\hline
\end{tabular}

* $\mathrm{P}=0.000 \otimes$ There were significant differences in the composition ratio of disease species in each year.

Table 4-The disease composition ratio in different year§(UNION囚n囚\%)) 


\begin{tabular}{|c|c|c|c|c|c|c|}
\hline & $\begin{array}{l}2015 \\
\bigotimes n=708 \rrbracket\end{array}$ & $\begin{array}{l}2016 \\
\bigotimes n=827 \rrbracket\end{array}$ & $\begin{array}{l}2017 \\
\bigotimes n=1009 \rrbracket\end{array}$ & $\begin{array}{l}2018 \\
\bigotimes n=1107 \rrbracket\end{array}$ & $\begin{array}{l}2019 \\
\bigotimes n=1318 \rrbracket\end{array}$ & $\begin{array}{l}2020 \\
\bigotimes n=922 \rrbracket\end{array}$ \\
\hline $\begin{array}{l}\text { Acute Appendicitis } \\
\bigotimes n=660 \rrbracket\end{array}$ & $92(13.0)$ & $114(13.8)$ & $126(12.5)$ & 107(9.7) & $143(10.8)$ & 78(8.5) \\
\hline $\begin{array}{l}\text { Acute Pancreatitis } \\
\bigotimes n=714 \rrbracket\end{array}$ & $60(8.5)$ & $77(9.3)$ & $106(10.5)$ & $165(14.9)$ & 188(14.3) & $114(12.4)$ \\
\hline $\begin{array}{l}\text { Biliary Tract } \\
\text { Inflammation } \\
\bigotimes n=624 \rrbracket\end{array}$ & $89(12.6)$ & $62(7.5)$ & $102(10.1)$ & $126(11.4)$ & $165(12.5)$ & $76(8.2)$ \\
\hline $\begin{array}{l}\text { Bowel Obstruction or } \\
\text { Bleeding }\end{array}$ & 133(18.8) & $142(17.2)$ & $226(22.4)$ & $225(20.3)$ & $240(18.2)$ & $160(17.4)$ \\
\hline $\begin{array}{l}\text { 囚n=1141区 } \\
\text { Esophageal and } \\
\text { Gastric Varices }\end{array}$ & $15(0,1)$ & 1000 & $15 / 1-1$ & 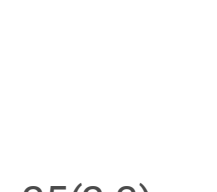 & 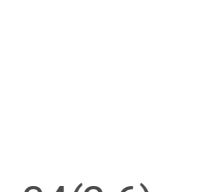 & 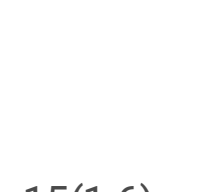 \\
\hline $\begin{array}{l}\text { Bleeding } \\
\bigotimes n=122 \rrbracket \\
\text { Hernia }\end{array}$ & $15(2.1)$ & 18(2.2) & 15(1.5) & $25(2.3)$ & $34(2.6)$ & 15(1.6) \\
\hline$\bigotimes n=113 \rrbracket$ & $17(2.4)$ & $18(2.2)$ & $18(1.8)$ & $14(1.3)$ & $30(2.3)$ & $16(1.7)$ \\
\hline $\begin{array}{l}\text { Liver Abscess or } \\
\text { Cancer } \\
\bigotimes n=123 \rrbracket\end{array}$ & $26(3.7)$ & $19(2.3)$ & $23(2.3)$ & $13(1.2)$ & 18(1.4) & $24(2.6)$ \\
\hline $\begin{array}{l}\text { Peptic Ulcer } \\
\bigotimes n=1962 \rrbracket\end{array}$ & $223(31.5)$ & $286(34.6)$ & $319(31.6)$ & $346(31.3)$ & 418(31.7) & $403(43.7)$ \\
\hline $\begin{array}{l}\text { Trauma } \\
\bigotimes n=422 \rrbracket\end{array}$ & $53(7.5)$ & $91(11.0)$ & $74(7.3)$ & $86(7.8)$ & $82(6.2)$ & $36(3.9)$ \\
\hline
\end{tabular}

$\S \mathrm{P}=0.000 \otimes T h e r e$ were significant differences in the composition ratio of disease species in each year.

Table 5-Comparison of peptic ulcer and other diseases in different years $₫ n \otimes \%)^{\#}$ 


\begin{tabular}{|c|c|c|c|c|c|c|c|}
\hline & 2015 & 2016 & 2017 & 2018 & 2019 & 2020 & $P$ \\
\hline PUTIAN & & & & & & & 0.000 \\
\hline Peptic ulcer & $132(16.6)$ & $168(20.0)$ & $136(16.6)$ & $170(18.3)$ & $205(21.1)$ & $426(37.1)$ & \\
\hline Others & $663(83.4)$ & $672(80.0)$ & $682(83.4)$ & $760(81.7)$ & $767(78.9)$ & $722(62.9)$ & \\
\hline UNION & & & & & & & 0.000 \\
\hline Peptic ulcer & $223(31.5)$ & $286(34.6)$ & $319(31.6)$ & $346(31.3)$ & $418(31.7)$ & $403(43.7)$ & \\
\hline Others & $485(68.5)$ & $541(65.4)$ & $690(68.4)$ & $761(68.7)$ & $900(68.3)$ & $519(56.3)$ & \\
\hline
\end{tabular}

\# Bonferroni method was used for multiple comparative analyses, and there was a statistical difference in the composition ratio between 2020 and each year from 2015 to 2019.

Figures 


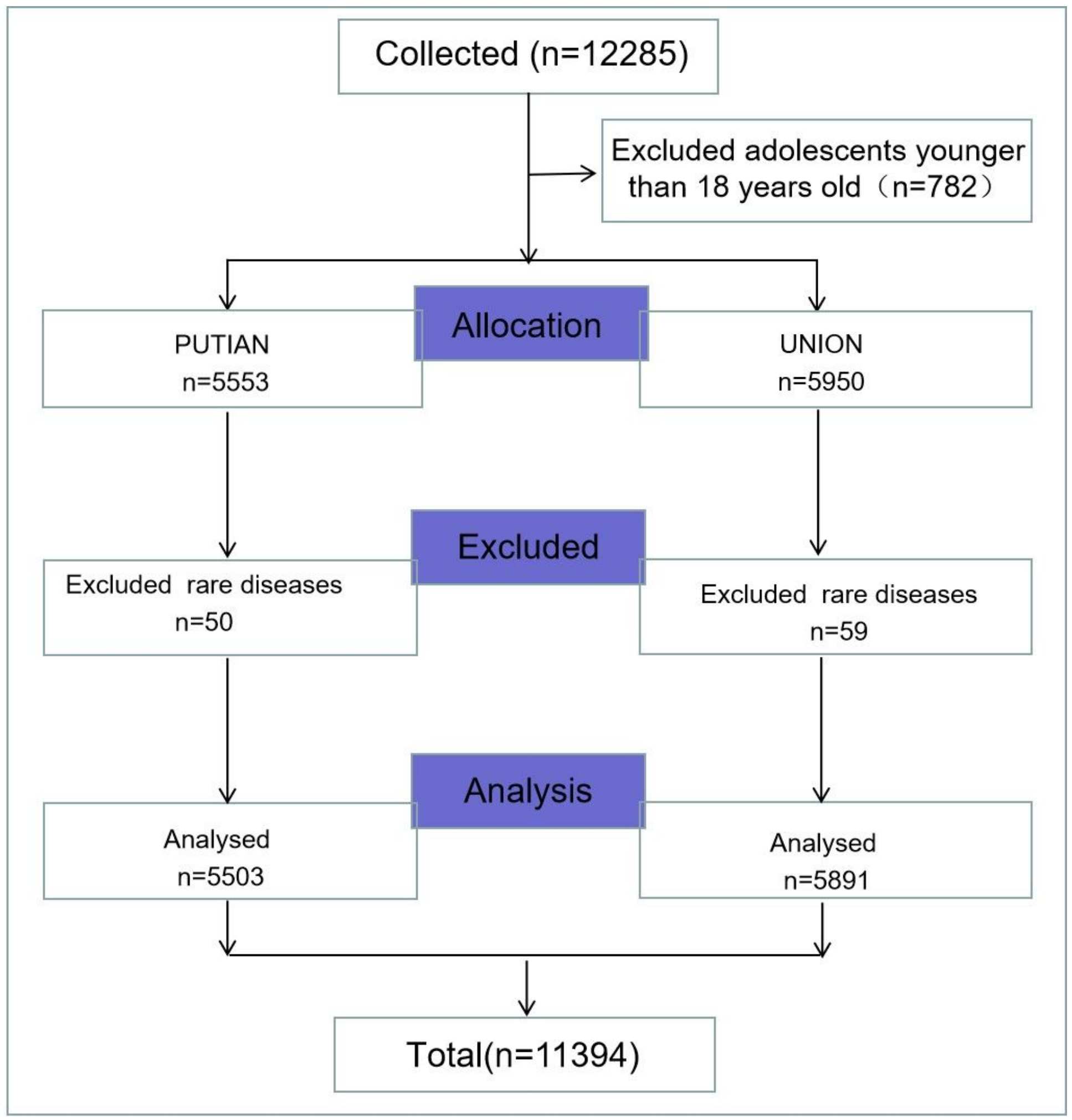

Figure 1

Research flow diagram. 
A

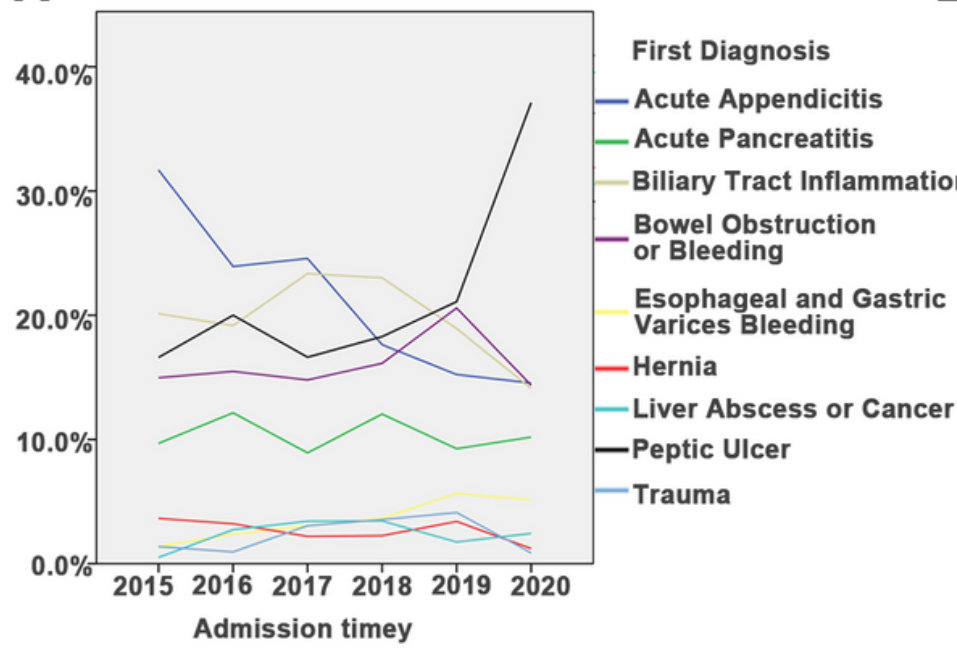

B

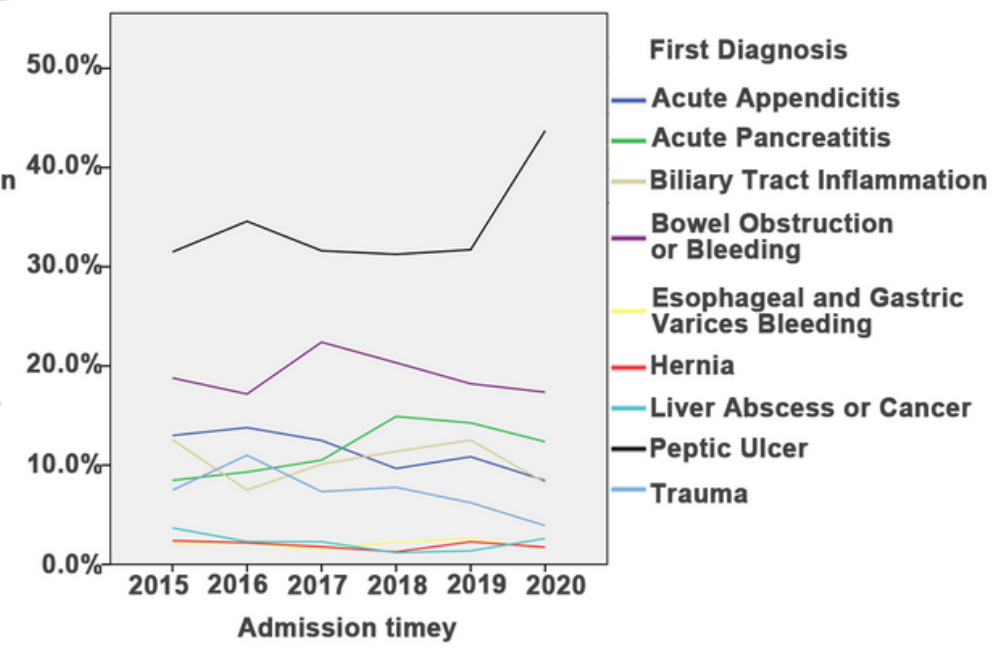

\section{Figure 2}

The changing trend of the disease composition ratio in different years in PUTIAN (A) and UNION (B).

A

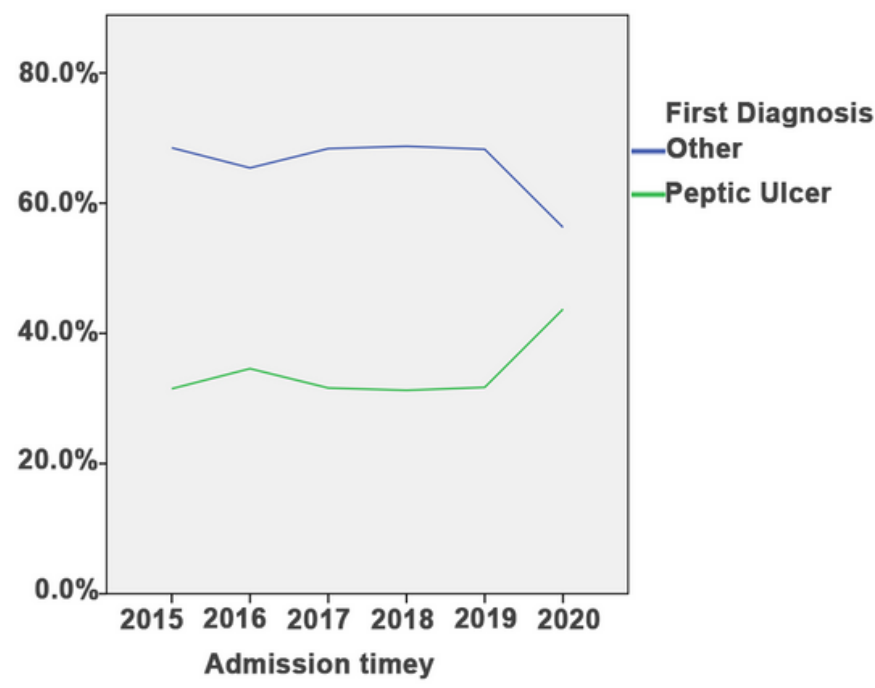

B

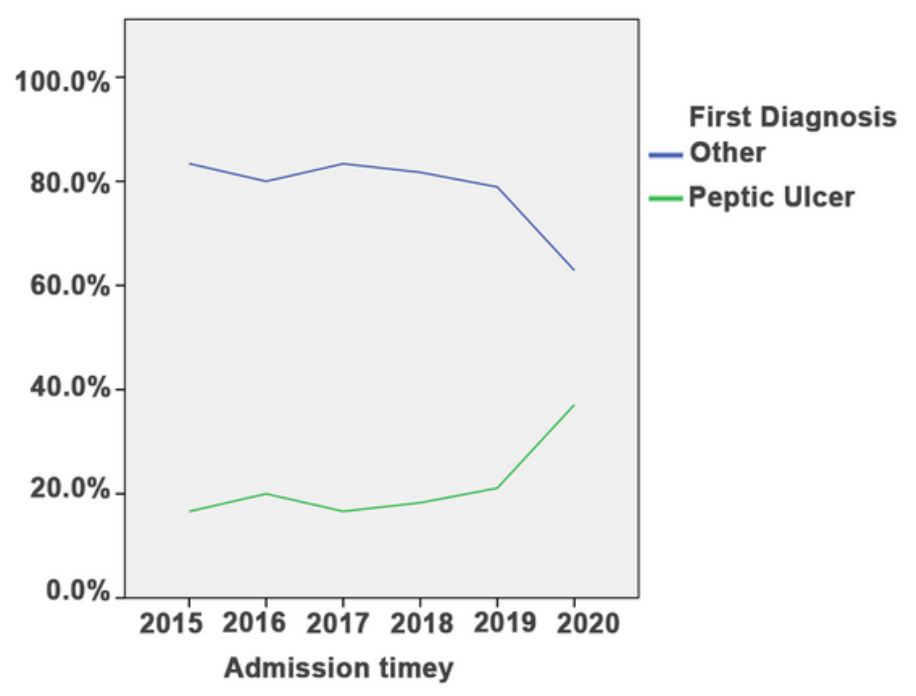

\section{Figure 3}

Comparison of peptic ulcer and other diseases in different years in PUTIAN(A) and UNION (B). 